\title{
Peptide methionine sulfoxide reductase (MsrA) is not a major virulence determinant for the oral pathogen Actinobacillus actinomycetemcomitans
}

\author{
Keith P. Mintz, ${ }^{1}$ Jackob Moskovitz, ${ }^{2}$ Hui $\mathrm{Wu}^{1}$ and Paula M. Fives-Taylor ${ }^{1}$
}

Author for correspondence: Keith P. Mintz. Tel: +1 802656 4271. Fax: +1 8026568749. e-mail:kmintz@zoo.uvm.edu

1 Department of Microbiology and Molecular Genetics, University of Vermont, Burlington, VT 05405, USA

2 Laboratory of Biochemistry, NHLBI, National Institutes of Health, Bethesda, MD, USA

\begin{abstract}
Actinobacillus actinomycetemcomitans is an oral pathogen that is a causative agent for periodontal disease as well as other non-oral infections. The chronic inflammation associated with periodontal diseases suggests that the bacterium must be able to neutralize oxygen intermediates to survive in the host tissues. Methionine sulfoxide reductase (MsrA) is an enzyme that has been demonstrated to have a role in protection against oxidative damage and has also been identified to be required for the proper expression or maintenance of functional adhesins on the surface of several pathogenic bacteria. The A. actinomycetemcomitans homologue of msrA has been isolated and a chromosomal insertion mutant constructed by allele replacement mutagenesis. Inactivation of the gene led to a complete loss of enzymic activity toward a synthetic substrate. However, the isogenic mutant was not more sensitive to oxidative stress or less adherent to epithelial cells as compared with the parent strain. These data suggest that this strain of $A$. actinomycetemcomitans has redundant systems that compensate for the MsrA activities ascribed for other organisms.
\end{abstract}

Keywords: adhesion, oxidative stress, periodontal disease

\section{INTRODUCTION}

Exposure to reactive oxygen intermediates such as superoxide anions, hydrogen peroxide and hydroxyl radicals, which are by-products of aerobic metabolism, can damage proteins, nucleic acids and cell membranes (Storz \& Imlay, 1999). These intermediates can oxidize methionine residues in proteins to methionine sulfoxide, which may result in the loss of the biological function of the protein (reviewed by Brot \& Weissbach, 1991). In vitro, the function can be restored by incubation of the oxidized protein with the enzyme methionine sulfoxide reductase, MsrA, in a thioredoxin-dependent reaction (Moskovitz et al., 2000).

MsrA is a ubiquitous enzyme that is found in a variety of animal tissues and organisms (Brot et al., 1981; Kuschel et al., 1999; Moskovitz et al., 1996a). The presence of MsrA in a variety of tissues and organisms suggests that this protein has an important function in providing cells

The GenBank accession number for the $m s r A$ sequence reported in this paper is AY026361. with a defence against oxidative stress. A role of MsrA in protecting cells against oxidative damage is supported by the decrease in viability of null mutants during oxidative stress (Dhandayuthapani et al., 2001; Hassouni et al., 1999; Moskovitz et al., 1995, 1998, 2001; Vriesema et al., 2000). Furthermore, the overexpression of MsrA in Escherichia coli, yeast and stable transfected human $\mathrm{T}$ cells provides higher resistance to hydrogen peroxide treatment (Moskovitz et al., 1995, 1998). In addition to a role in protection to oxidative damage, MsrA has been proposed to be a virulence factor for numerous micro-organisms. Inactivation of $m s r A$ reduces bacterial adhesion of Streptococcus pneumoniae to human cells and reduces type I fimbriaemediated haemagglutination of red blood cells by enteropathogenic E. coli (Wizemann et al., 1996). This enzyme has also been shown to be a virulence determinant in Erwinia chrysanthemi, Mycoplasma genitalium and Staphylococcus aureus (Dhandayuthapani et al., 2001; Hassouni et al., 1999; Singh et al., 2001).

The oral pathogen Actinobacillus actinomycetemcomitans is implicated as the causative agent of localized 
juvenile periodontal disease as well as various forms of adult periodontitis and other non-oral infections (Asikainen \& Alaluusua, 1993; Kaplan et al., 1989; Slots et al., 1986; Zambon, 1985). Periodontal diseases are chronic inflammatory diseases that are mediated in part by virulence factors that are capable of direct tissue damage (Fives-Taylor et al., 1999). In addition, the host also mediates much of the pathogenic effects of the bacteria through a multitude of immune mediators including neutralization of the bacteria by oxidative mechanisms (Zadeh et al., 1999). Therefore, it was of interest to determine if $m s r A$ is present in the $A$. actinomycetemcomitans genome and if this enzyme contributes to the virulence of this pathogen. In the present study, the gene encoding MsrA of A. actinomycetemcomitans was identified and isolated. An isogenic mutant was developed by allele replacement mutagenesis and the functions associated with MsrA activity in other organisms were investigated.

\section{METHODS}

Bacterial strains and plasmids. The A. actinomycetemcomitans strains developed in this study are derived from the clinical strain SUNY 465. All A. actinomycetemcomitans strains were grown statically in Trypticase soy broth supplemented with $0.6 \%$ yeast extract (TSBYE) in a humidified $10 \% \mathrm{CO}_{2}$ atmosphere at $37^{\circ} \mathrm{C}$. All E. coli strains: JM109, DH5 $\alpha$ ( $\lambda$ pir) and SM10( $\lambda$ pir) were grown in Luria-Bertani (LB) broth at $37^{\circ} \mathrm{C}$ with aeration. The non-replicating (in $A$. actinomycetemcomitans) mobilizable plasmid pVT1461 was constructed as described by Mintz et al. (2002). The strains and plasmids used in this study are listed in Table 1.

Cloning and sequence of the $\boldsymbol{A}$. actinomycetemcomitans msrA. Conserved amino acid sequences of MsrA from Str. pneumoniae and Neisseria gonorrhoeae were used as a probe to detect the presence of a homologous protein sequence deduced from the available $A$. actinomycetemcomitans strain HK1651 DNA sequence at the University of Oklahoma. Based on this homology, oligonucleotide primers were synthesized (Operon Technologies) to amplify the A. actinomycetemcomitans msrA including flanking regions from the chromosome of strain SUNY 465. A DNA fragment was generated in a PCR reaction using Taq polymerase (Gibco BRL) using the sense primer corresponding to a sequence $356 \mathrm{bp} 5^{\prime}$ to the start codon of $m s r A$ (5'-CACACGACTGTCCGAAC-3') and the antisense sequence $432 \mathrm{bp} 3^{\prime}$ from the stop codon of the gene (5'-CGTAGACAAGACCGCAACA-3') of strain HK1651 in a Perkin-Elmer PCR machine. The PCR products were separated by agarose gel electrophoresis and a $1860 \mathrm{bp}$ fragment was purified using QIAquick gel extraction kit following the manufacturer's directions (Qiagen) and ligated with the T/A cloning vector, pGEM T-Easy (Promega). The ligation mixture was transformed into JM109 E. coli cells and plated on LB agar plates containing $50 \mu \mathrm{g}$ ampicillin $\mathrm{ml}^{-1}$, IPTG and X-Gal (Sambrook et al., 1989). Plasmids with disrupted $\beta$-gal were purified, restricted with EcoRI to release the insert and characterized by agarose gel electrophoresis. An individual plasmid containing the correct size insert was used for sequencing. Both DNA strands of the insert were sequenced using the dideoxy terminator cycle sequencing kit (Applied Biosystems) and analysed using an Applied Biosystems automated DNA sequencer. DNA sequencing was performed at the Vermont Cancer Center DNA Analysis Facility. The complete $m s r A$ sequence can be obtained from GenBank (accession no. AY026361).

Allele replacement mutagenesis. A unique StuI restriction site within $m s r A$ was engineered by inverse PCR (Ochman et al., 1989 ) of the $\mathrm{T} / \mathrm{A}$ cloning vector containing the $1.8 \mathrm{~kb}$ DNA fragment. The primers used will result in a loss of $500 \mathrm{bp}$ of the coding region of $m s r A$. The spectinomycin gene from plasmid pDL269 (LeBlanc et al., 1991) was isolated and ligated with the inverse PCR product restricted with StuI (Mintz \& FivesTaylor, 2000). The ligation mixture was transformed into $E$. coli JM109 cells by electroporation and plated on LB agar plates containing $50 \mu \mathrm{g}$ spectinomycin $\mathrm{ml}^{-1}$. Spc ${ }^{\mathrm{r}}$ colonies were selected and the plasmids isolated using a rapid plasmid purification scheme (Berghammer \& Auer, 1993). The construct was confirmed by restriction mapping and PCR. The disrupted gene was released from the plasmid by digestion with EcoRI and ligated with the mobilizable plasmid pVT1460 restricted with EcoRI (Mintz et al., 2002). Electrocompetent DH5 $\alpha$ ( $\lambda$ pir $)$ cells were transformed with the ligation mixture and transformants were selected on LB agar containing $50 \mu \mathrm{g}$ Spc $\mathrm{ml}^{-1}$. Plasmids were isolated and the construct was confirmed by PCR. Plasmid containing the disrupted gene was purified using Qiagen spin columns and transformed by electroporation into E. coli SM10( $\lambda$ pir) cells for conjugation. Mobilization of the plasmid containing the disrupted gene from E. coli SM10( $\lambda$ pir) to A. actinomycetemcomitans strain VT1169 $\left(\mathrm{Rif}^{\mathrm{r}} / \mathrm{Nal}^{\mathrm{r}}\right)$ was accomplished by conjugation as described previously (Mintz \& Fives-Taylor, 2000). Bacteria

Table 1. Bacterial strains and plasmids

\begin{tabular}{|c|c|c|}
\hline Strain/plasmid & Description & Source/reference \\
\hline \multicolumn{3}{|l|}{ Strain } \\
\hline $\begin{array}{l}\text { A. actinomycetemcomitans } \\
\text { VT1169 }\end{array}$ & Parent strain, $\mathrm{Nal}^{\mathrm{r}} \mathrm{Rif}^{\mathrm{r}}$ & $\begin{array}{l}\text { Mintz \& Fives-Taylor } \\
(2000)\end{array}$ \\
\hline $\begin{array}{l}\text { A. actinomycetemcomitans } \\
\text { VT1530 }\end{array}$ & VT1169 msrA, Nal ${ }^{\mathrm{r}}$ Rif $^{\mathrm{r}} \mathrm{Spc}^{\mathrm{r}}$ & This work \\
\hline \multicolumn{3}{|l|}{ Plasmid } \\
\hline pVT1460 & Mobilizable plasmid, $\mathrm{Kan}^{\mathrm{r}}$ & Mintz et al. (2002) \\
\hline pPK1 & Replicating plasmid, $\mathrm{Spc}^{\mathrm{r}}$ & LeBlanc et al. (1993) \\
\hline pVT1503 & Replicating plasmid, $\operatorname{Kan}^{\mathrm{r}}$ & This work \\
\hline pVT1544 & $1.86 \mathrm{~kb} m s r A$ fragment in pVT1503, $\operatorname{Kan}^{\mathrm{r}}$ & This work \\
\hline
\end{tabular}


were plated on TSBYE agar containing Nal, Rif and Spc (50, 100 and $50 \mu \mathrm{g} \mathrm{ml}^{-1}$, respectively) and incubated as described above for 3-4 days. Spectinomycin-resistant colonies were replica-plated on TSBYE plates containing $100 \mu \mathrm{g} \mathrm{Kan} \mathrm{ml}^{-1}$. Bacteria that were $\mathrm{Spc}^{\mathrm{r}}$, $\mathrm{Kan}^{\mathrm{s}}$ were analysed by colony PCR to confirm the presence of mutant msrA. The allelic replacement of the genomic copy of $m s r A$ was confirmed by Southern blot analysis.

Plasmid construction for restoration of MsrA activity in $\boldsymbol{A}$. actinomycetemcomitans. A derivative of the A. actinomycetemcomitans replicating plasmid pPK1 (LeBlanc et al., 1993), pVT1503 was used to restore MsrA activity in the $m s r A$ mutant. The spectinomycin adenyltransferase (aad9) was deleted by incubation with $K p n \mathrm{I}$ and $\mathrm{BamHI}$ and then separated by agarose gel electrophoresis. The aminoglycoside phosphotransferase gene $(k a n)$ derived from pUC-4K (Pharmacia Biotech) previously subcloned into the SmaI site of pBluescript II SK (Stratagene), was isolated following restriction with $K p n \mathrm{I}$ and BamHI. The $1.1 \mathrm{~kb}$ DNA fragment containing kan was ligated with the pPKI plasmid backbone, transformed into E. coli JM109 cells and grown on LB agar plates containing $50 \mu \mathrm{g}$ kanamycin $\mathrm{ml}^{-1}$. Transformants were confirmed by restriction analysis.

The $m s r A$ and flanking regions derived from amplification of chromosomal DNA from A. actinomycetemcomitans SUNY 465 (described above) was released from the T/A cloning vector by incubation with EcoRI and purified by gel electrophoresis. The purified product was ligated with pVT1503 restricted with EcoRI, transformed into E. coli JM109 cells and selected on Kan plates. The purified plasmid was transferred into A. actinomycetemcomitans by electroporation as described previously (Sreenivasan et al., 1991).

Southern analysis. msrA strains were grown in TSBYE containing $50 \mu \mathrm{g} \mathrm{Spc} \mathrm{ml} \mathrm{m}^{-1}$ and the DNA isolated using Puregene DNA extraction kit (Gentra Systems). Chromosomal DNA was restricted with EcoRI and the fragments separated on a $0.7 \%$ agarose gel in TAE buffer. The DNA fragments were transferred to Hybond nylon membranes (Amersham Life Sciences) and the membranes were treated following the method of Sambrook et al. (1989). The membranes were hybridized with DNA probes conjugated with horseradish peroxidase using the conditions suggested by the manufacturer (Amersham Life Sciences). Hybridizing fragments were visualized using the ECL detection system (Amersham Life Sciences) and exposure to photographic film (XAR-5, Eastman Kodak).

Determination of MsrA activity. Overnight bacterial cultures $(50 \mathrm{ml})$ were harvested by centrifugation and the bacteria resuspended in $400 \mu \mathrm{PBS}$ containing $2 \mathrm{mM}$ PMSF and $1 \mathrm{mM}$ EDTA, $\mathrm{pH} 8 \cdot 0$. The bacteria were disrupted by the addition of $70 \mathrm{mg}$ glass beads $(150-212 \mu \mathrm{m}$, Sigma) and shaking in a Fast Prep FP120 (Savant Instruments) at setting 6 with $4 \times 30 \mathrm{~s}$ pulses at $4{ }^{\circ} \mathrm{C}$. Whole bacteria and membrane fragments were collected by centrifugation for $20 \mathrm{~min}$ at $20000 \mathrm{~g}$ at $4{ }^{\circ} \mathrm{C}$. The supernatants were removed, snap-frozen in methanol/dry ice and stored at $-80^{\circ} \mathrm{C}$. Protein concentrations were determined by the BCA Protein Assay Kit following the manufacturer's instructions (Pierce) with BSA as the standard. The reduction of protein-bound methionine sulfoxide by MsrA was assayed using dabsyl-Met $(\mathrm{O})$ as described previously (Moskovitz et al., 1999, 2000). Briefly, $200 \mu \mathrm{M}$ dabsyl-Met $(\mathrm{O})$ was incubated with cell extract or recombinant pure protein in the presence of $20 \mathrm{mM}$ DTT and $20 \mathrm{mM}$ Tris/ $\mathrm{HCl}, \mathrm{pH} \mathrm{7 \cdot 4.}$ Following incubation at $37^{\circ} \mathrm{C}$ for $30 \mathrm{~min}$, formation of dabsyl-Met was analysed by product separation on a reverse phase C-18 column using HPLC system, as previously described (Moskovitz et al., 1999).

To differentiate between the presence of the enzyme in the cytoplasmic and periplasmic space, spheroplasts were generated by incubation of bacteria with $30000 \mathrm{U}$ lysozyme in the presence of $20 \%$ sucrose, $1 \mathrm{mM}$ EDTA, pH $8 \cdot 0$, for $5 \mathrm{~min}$ on ice (Feilmeier et al., 2000). The resulting spheroplasts were recovered by centrifugation for $2 \mathrm{~min}$ at $12000 \mathrm{~g}$. The supernatant containing the periplasmic proteins was made to $1 \mathrm{mM}$ PMSF and stored frozen at $-80^{\circ} \mathrm{C}$ before assaying for MsrA activity. The pellet was resuspended in $1 \mathrm{ml}$ water containing $1 \mathrm{mM}$ EDTA, pH 8.0 and $1 \mathrm{mM}$ PMSF, mixed thoroughly and incubated at room temperature for $5 \mathrm{~min}$. The cytoplasmic proteins were recovered in the supernatant obtained by centrifugation at $138000 \mathrm{~g}$ for $1 \mathrm{~h}$ following the disruption of the spheroplasts with water. The cytoplasmic proteins were removed and stored at $-80^{\circ} \mathrm{C}$ before assaying for MsrA activity.

Disk inhibition assay. Bacterial cells were grown to exponential or stationary phase in TSBYE media and equal numbers of bacteria $\left(10^{8}\right)$ were diluted in TSBYE agar at $42^{\circ} \mathrm{C}$ and poured into plates. A $6 \mathrm{~mm}$ filter disk was placed in the centre of the agar plate and a $15 \mu \mathrm{l}$ aliquot of hydrogen peroxide (100$1000 \mathrm{mM}$ ) was applied to the disk. The plates were incubated overnight as described above.

Adhesion of $\boldsymbol{A}$. actinomycetemcomitans to epithelial cells and intramacrophage survival. The adherence of A. actinomycetemcomitans to the KB oral carcinoma human epithelial cell line was performed as previously described using an ELISA format (Mintz \& Fives-Taylor, 1994). RAW 264.7 murine macrophages derived from BALB/c mice (ATCC TIB71) were used for intramacrophage survival studies. The cells were grown under $5 \% \mathrm{CO}_{2}$ in Dulbecco's Modified Eagle's Medium (DMEM) supplemented with $10 \%$ foetal bovine serum containing $4 \mathrm{mM}$ L-glutamine, $1 \mathrm{mM}$ pyruvate, $0 \cdot 15 \%$ sodium bicarbonate and $0.45 \%$ glucose at $37^{\circ} \mathrm{C}$. All cells were used between passages 3 and 20 of the ATCC stock.

Intramacrophage survival was assessed using the gentamicinprotection assay as described by Guy et al. (2000). Cells were seeded into wells of sterile 24-well tissue culture plates and incubated for $24 \mathrm{~h}$ as described above. Macrophages $\left(5 \times 10^{5}\right)$ were infected at a m.o.i. of $\sim 50: 1$ with bacteria grown to mid-exponential phase. The plates were centrifuged at $\sim 170 \mathrm{~g}$ for $5 \mathrm{~min}$ to synchronize infection and incubated for $20 \mathrm{~min}$ to allow internalization. The infected monolayers were washed twice with PBS at $37^{\circ} \mathrm{C}$ followed by addition of warmed DMEM ( $1 \mathrm{ml}$ per well) containing $100 \mu \mathrm{g}$ gentamicin $\mathrm{ml}^{-1}$ to kill extracellular bacteria. After $2 \mathrm{~h}$, the growth medium was replaced with DMEM containing $10 \mu \mathrm{g}$ gentamicin $\mathrm{ml}^{-1}$ to minimize the killing of intracellular bacteria. At the desired time points, the appropriate wells were washed twice with pre-warmed PBS and the monolayers were lysed by incubation in $1 \%$ Triton X-100 in PBS $(0.5 \mathrm{ml}$ per well $)$ for $10 \mathrm{~min}$. Following vigorous mechanical disruption, the lysate was diluted in PBS and plated onto TSBYE agar plates. The plates were incubated for 2 days as described above and the colonies were counted.

\section{RESULTS}

\section{Isolation of $A$. actinomycetemcomitans $m s r A$}

The gene encoding MsrA was identified in A. actinomycetemcomitans using a conserved sequence of the protein to probe the available genomic sequence of $A$. 


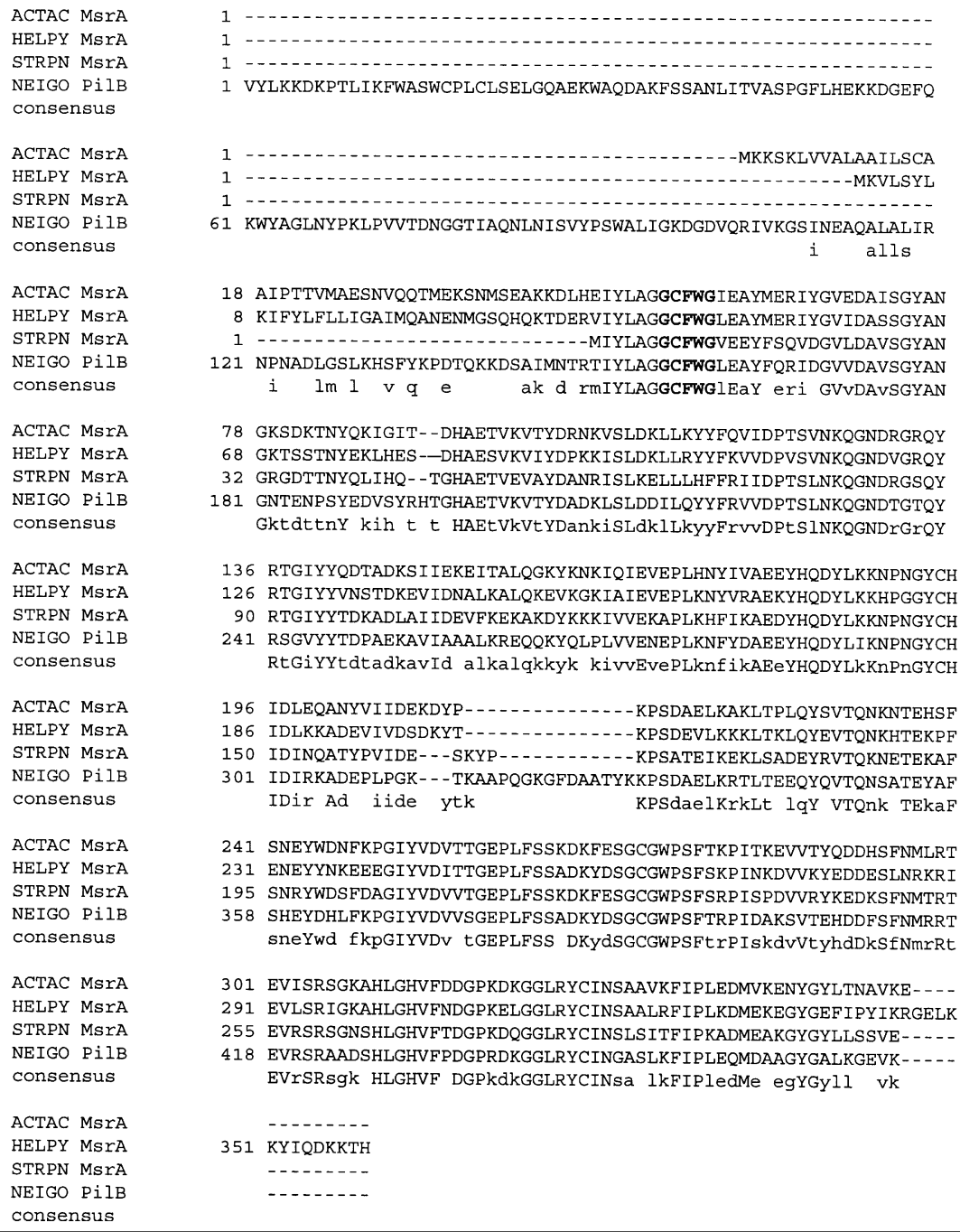

18 AIPTTVMAESNVQQTMEKSNMSEAKKDLHEIYLAGGCFWGIEAYMERIYGVEDAISGYAN 8 KIFYLFLLIGAIMQANENMGSQHQKTDERVIYLAGGCFWGLEAYMERIYGVIDASSGYAN 1 121 NPNADLGSLKHSFYKPDTOKKDSAIMNTRTIYLAGGCFWGLEAYFORIDGVDAVSGYAN i $I \mathrm{~m} I \mathrm{v} q \mathrm{a}$ ak d rmIYLAGGCFWGIEaY eri GVVDAvSGYAN

78 GKSDKTNYQKIGIT--DHAETVKVTYDRNKVSLDKLLKYYFQVIDPTSVNKQGNDRGRQY 68 GKTSSTNYEKLHES--DHAESVKVIYDPKKISLDKLLRYYFKVVDPVSVNKQGNDVGRQY 32 GRGDTTNYQLIHQ - TGHAETVEVAYDANR ISLKELLLHFFRI IDPTSLNKOGNDRGSOY 181 GNTENPSYEDVSYRHTGHAETVKVTYDADKLSLDDIIOYYFRVVDPTSINKQGNDTGTOY GktdttnY kih t $t$ HAEtVkVtYDankisLdklLkyYFrvVDPtSINKQGNDrGrQY

136 RTGIYYQDTADKSIIEKEITALQGKYKNKIQIEVEPLHNY IVAEEYHQDYLKKNPNGYCH 126 RTGIYYVNSTDKEVIDNALKALQKEVKGKIAIEVEPLKNYVRAEKYHQDYLKKHPGGYCH 90 RTGIYYTDKADLAIIDEVFKEKAKDYKKKIVVEKAPLKHFIKAEDYHQDYLKKNPNGYCH 241 RSGVYYTDPAEKAVIAAALKREQQKYQLPLVVENEPLKNFYDAEEYHQDYLIKNPNGYCH RtGiYYtdtadkavId alkalqkkyk kivvEvePLknfikAEeYHQDYLkKnPnGYCH

196 IDLEQANYVIIDEKDYP-- - - - - - KPSDAELKAKLTPLQYSVTQNKNTEHSF 186 IDLKKADEVIVDSDKYT--...-- - - KPSDEVLKKKLTKLQYEVTQNKHTEKPF 150 IDINQATYPVIDE---SKYP---.-- - - - KPSATEIKEKLSADEYRVTQKNETEKAF 301 IDIRKADEPLPGK--- TKAAPQGKGFDAATYKKPSDAELKRTLTEEQYQVTQNSATEYAF IDir Ad iide ytk KPSdaelkrkLt lqY VTQnk TEkaF

241 SNEYWDNFKPGIYVDVTTGEPLFSSKDKFESGCGWPSFTKPITKEVVTYQDDHSFNMLRT 231 ENEYYNKEEEGIYVDITTGEPLFSSADKYDSGCGWPSFSKP INKDVVKYEDDESLNRKRI 195 SNRYWDSFDAGIYVDVVTGEPLFSSKDKFESGCGWPSFSRPISPDVVRYKEDKSFNMTRT 358 SHEYDHLFKPGIYVDVVSGEPLFSSADKYDSGCGWPSFTRPIDAKSVTEHDDFSFNMRRT sneYwd fkpGIYVDv tGEPLFSS DKydSGCGWPSFtrPIskdvVtyhdDkSfNmrRt

301 EVISRSGKAHLGHVFDDGPKDKGGLRYCINSAAVKFIPLEDMVKENYGYLTNAVKE - - 291 EVLSR IGKAHLGHVFNDGPKELGGLRYCINSAALRF I PLKDMEKEGYGEF I PY IKRGELK 255 EVRSRSGNSHLGHVFTDGPKDQGGLRYCINSLS ITF IPKADMEAKGYGYLLSSVE - ... 418 EVRSRAADSHLGHVFPDGPRDKGGLRYCINGASLKF IPLEQMDAAGYGALKGEVK--.EVrSRsgk HLGHVF DGPkdkGGLRYCINsa lkFIPledMe egYGyll vk

- - - - - - -

351 KYIQDKKTH

(1).-.-

Fig. 1. Sequence alignment of MsrA from $A$ actinomycetemcomitans. The alignment was generated using CLUSTAL W (http://www. clustalw.genome.ad.jp/) and Boxshade 3.21 (http://www.ch.embnet.org/software/BOX form.html). The putative active site of MsrA is shown in bold. ACTAC, A. actinomycetemcomitans; HELPY, H. pylori (Cao et al., 1998; Tomb et al., 1997); STRPN, Str. pneumoniae (Wizemann et al., 1996); NEIGO, N. gonorrhoeae (Taha et al., 1988; Wizemann et al., 1996). actinomycetemcomitans. The entire ORF and adjoining sequences were amplified by PCR and sequenced. The ORFs flanking $m s r A$ were found to encode a homologue of carbonic anhydrase (upstream) and cytochrome ctype biogenesis protein which has some homology to MsrB (downstream) of MsrA. The $m s r A$ DNA sequence determined from the strain used in this study (SUNY 465) was identical to the prototype strain HK1651 sequenced at the University of Oklahoma.

A BLAST search of the amino acid sequence deduced from the ORF revealed homology with the MsrA protein of multiple bacterial species. Alignment of the protein sequence (Fig. 1) indicated that the A. actinomycetemcomitans protein had the highest sequence homology with MsrA of Helicobacter pylori (66\% identical amino acids). The protein sequence was also homologous to the MsrA of Str. pneumoniae (58\% identical amino acids) except the sequence alignment started 46 aa from the amino terminus of the MsrA of A. actinomycetemcomitans. Homology was also noted within the protein encoded by pilB of N. gonorrhoeae $(54 \%$ identical amino acids). The $A$. actinomycetemcomitans sequence contains the putative active site of MsrA, GCFWG, (corresponding to aa 54-58 in Fig. 1) as determined for the Saccharomyces cerevisiae homologue (Moskovitz et al., 2000).

\section{Cellular localization of MsrA}

The amino terminal sequence of MsrA of A. actinomycetemcomitans displays features that are characteristic of prokaryotic signal sequences (von Heijne, 1986). A run of charged amino acids after the start methionine is followed by a central hydrophobic region and then a more polar $\mathrm{COOH}$-terminal domain adjacent to the mature protein. Following this polar amino acid region, a putative signal peptidase cleavage site (the 17 th amino acid, ala, from the start methionine) is predicted (von Heijne, 1986).

Cellular fractionation studies indicated that the MsrA enzyme activity was strictly associated with the soluble

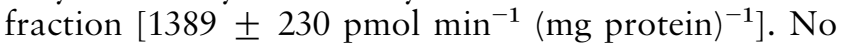
activity was associated with the membrane fraction. However, assay of the cytoplasmic and periplasmic space fractions showed that the MsrA activity was equally distributed between the two compartments 
(a)

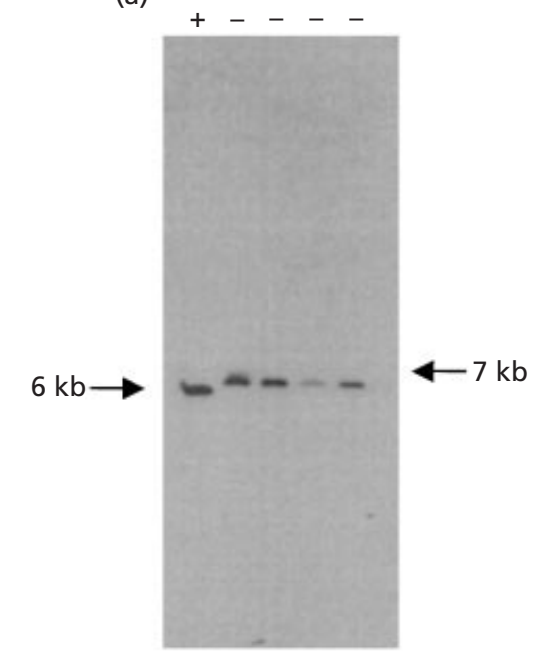

(b)

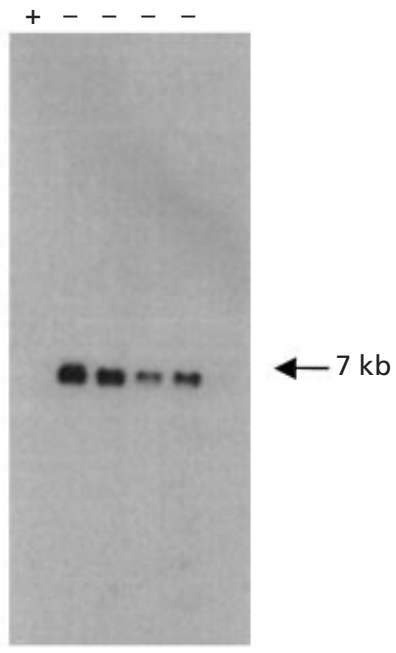

Fig. 2. Southern blot analysis of chromosomal DNA. Chromosomal DNA was isolated from wild-type and msrA strains and incubated with EcoRI. Products were separated by agarose gel electrophoresis and transferred to nylon membranes. Duplicate membranes were probed with labelled msrA (a) or spectinomycin adenyltransferase (aad9) (b). +, wild-type DNA; -, mutant DNA. Arrows correspond to migration of selected DNA markers.

Table 2. Measurement of MsrA enzyme activity

\begin{tabular}{|c|c|}
\hline Strain & $\begin{array}{c}\text { Dabsyl-met }(\mathrm{O}) \text { reduced } \\
{\left[\mathrm{pmol} \mathrm{min}^{-1}(\mathrm{mg} \text { protein })^{-1}\right]}\end{array}$ \\
\hline VT1169 (Parent strain) & $1389 \pm 230$ \\
\hline $\operatorname{VT} 1530(m s r A)$ & 0 \\
\hline VT1530/pVT1544 (msrA/msr $A^{+}$on pVT1503) & $1788 \pm 282$ \\
\hline VT1530/pVT1503 (msrA/plasmid backbone) & 0 \\
\hline VT1169/pVT1503 (Parent strain/plasmid backbone) & 1028 \\
\hline VT1169/pVT1544 (Parent strain/msr $A^{+}$on pVT1503) & $17100 \pm 2582$ \\
\hline
\end{tabular}

(7043 and $6715 \mathrm{U}$, respectively), indicating that the enzyme may be transported across the inner membrane.

\section{Inactivation of the gene encoding MsrA activity}

The gene encoding MsrA was inactivated by insertion of an antibiotic cassette encoding resistance to spectinomycin into an engineered restriction site that resulted in the loss of $\sim 500 \mathrm{bp}$ of the coding region. This construct was transferred to A. actinomycetemcomitans by conjugation and transconjugants were selected for spectinomycin resistance. Transconjugants were analysed for the disruption of $m s r A$ by colony PCR and the allele replacement of the genomic copy of $m s r A$ was confirmed by Southern blot analysis (Fig. 2). A $6 \mathrm{~kb}$ EcoRI fragment hybridized with the $m s r A$ probe in the lane corresponding to the wild-type DNA, whereas a larger fragment $(\sim 6.6 \mathrm{~kb})$ hybridized with the probe in all four putative mutant strains. An identical blot probed with $s p c$ hybridized exclusively with the fragment corresponding to the disrupted $m s r A$ in the blot in Fig. 2(b). Signal was absent in the lane corresponding to the wildtype DNA. No signal was generated in any of the lanes when the plasmid without insert was used as the probe (data not shown). These data indicate that the disrupted gene replaced the wild-type gene in the $A$. actinomycetemcomitans genome in a site-directed and specific manner. One of these strains was further characterized.

\section{Characterization of $A$. actinomycetemcomitans MsrA activity}

MsrA activity was determined using dabsyl-Met $(\mathrm{O})$ as the substrate, as described previously (Moskovitz et al., 2000). The MsrA activity of A. actinomycetemcomitans was found to be comparable to the activity found for other bacterial species (Table 2). A complete absence of MsrA activity was observed for the $m s r A$ mutant strain, verifying that the targeted gene is linked with MsrA activity. The activity was restored to wild-type levels when a replicating plasmid containing the complete $m s r A$ sequence was introduced into the mutant strain by electroporation (see Table 2). Transformation of the mutant or wild-type strain with the plasmid vector did not significantly alter the enzymic activity. Overexpression of MsrA activity was observed when the plasmid containing $m s r A$ was transformed into the wild-type strain.

Oxidation of methionine residues by biologically reactive oxygen intermediates, such as superoxides, hydrogen peroxide and hydroxyl radicals may lead to the loss of biological function (Brot \& Weissbach, 1991). The role of $m s r A$ in oxidative stress in $A$. actinomycetemcomitans was investigated by several approaches. The sensitivity of $A$. actinomycetemcomitans to hydrogen peroxide was investigated using disk inhibition assays. Concentrations of hydrogen peroxide 
Table 3. Effect of $\mathrm{H}_{2} \mathrm{O}_{2}$ treatment on $A$. actinomycetemcomitans growth

\begin{tabular}{|ccc|}
\hline \multirow{2}{*}{$\begin{array}{c}\mathrm{H}_{2} \mathrm{O}_{2} \\
(\mathbf{m M})\end{array}$} & \multicolumn{2}{c|}{ Area of growth inhibition $\left(\mathrm{cm}^{2}\right)^{*}$} \\
\cline { 2 - 3 } & VT1169 (Wild-type) & VT1530 $(\boldsymbol{m s r} \boldsymbol{A})$ \\
\hline 100 & $20 \pm 10$ & $20 \pm 8$ \\
250 & $47 \pm 12$ & $43 \pm 10$ \\
500 & $66 \pm 17$ & $61 \pm 12$ \\
1000 & $87 \pm 19$ & $84 \pm 17$ \\
\hline
\end{tabular}

* The amount of growth inhibition was calculated as the area of the clear zone minus the area of the disk. Data are expressed as the mean \pm standard deviation for a minimum of six independent determinations.

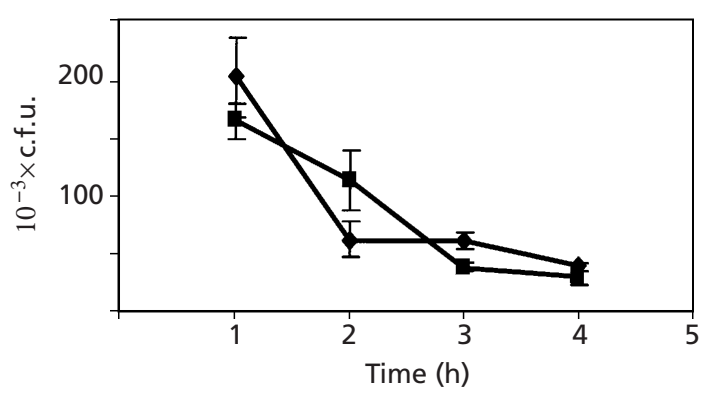

Fig. 3. Intramacrophage survival of $A$. actinomycetemcomitans $m s r A^{+}$and $m s r A^{-}$strains. Equal numbers of wild-type $(\diamond)$ and mutant ( $\square$ ) bacteria were incubated with mouse macrophages. Bacterial survival was determined using a gentamicin protection assay. At the indicated times, cells were disrupted with detergent and the bacteria were plated. The values are the means of two experiments, each time point was performed in triplicate.

were varied from $100 \mathrm{mM}$ to $1 \mathrm{M}$ and the zone of growth inhibition was similar for the mutant as compared with the parent strain (Table 3) at all concentrations. Similar results were obtained when stationary phase bacteria were used in the assay. No difference in the growth inhibition was observed with $1 \%$ to $3.8 \%$ paraquat (methyl viologen), an uncoupler of oxidative phosphorylation, which leads to superoxide production (data not shown).

Growth conditions were varied to determine if environmental factors regulated the expression of msrA. No difference in the area of growth inhibition between the wild-type and mutant strains was observed when the bacteria were grown and plated under anaerobic conditions, at an acidic $\mathrm{pH}(6.5$ versus $7 \cdot 2)$ or in the presence of cysteine, which can substitute for yeast extract in the growth media (Sreenivasan et al., 1993) (data not shown). To exclude the possibility that the growth media may be masking the difference between the two strains, equal numbers of bacteria were washed with PBS and resuspended in PBS containing $1 \mathrm{mM}$ hydrogen peroxide. Aliquots were taken at timed intervals and plated to determine bacterial viability. Again, no difference in viability over time was observed (data not shown).

Mononuclear phagocytes, including macrophages and monocytes, are present in diseased periodontal tissues and participate in host defence processes. Therefore, to determine if this gene product is involved in the survival of the bacterium in a more biologically relevant system, both strains were tested for survival inside macrophages. Uptake of approximately equal numbers of bacteria was synchronized by centrifugation and incubation at $37^{\circ} \mathrm{C}$ for $20 \mathrm{~min}$ before the addition of antibiotic to kill external bacteria. The survival kinetics of the wild-type and mutant strains are depicted in Fig. 3. These data clearly demonstrate that A. actinomycetemcomitans is rapidly killed following internalization by macrophages. In addition, the data also suggest that the survival kinetics of the wild-type and the $m s r A$ null mutant strains are similar. These data indicate that inactivation of MsrA does not affect the intracellular survival of $A$. actinomycetemcomitans in macrophages.

MsrA activity has been demonstrated to be important in maintaining bacterial surface structures involved in adhesion (Wizemann et al., 1996). Therefore, we investigated the adhesion properties of the $m s r A$ null mutant to human epithelial cells. Equal numbers of bacteria (wildtype and mutant) were incubated with the epithelial cells and bacterial binding was detected by purified anti- $A$. actinomycetemcomitans immunoglobulins. No difference in the binding of the mutant compared with the parent strain to epithelial cells was detected $(0 \cdot 6 \pm 0 \cdot 07$ vs $0.6 \pm 0.03$ relative absorbance units, respectively). These data suggest that MsrA is not involved in maintaining the adhesin(s) required for binding to epithelial cells in this strain of A. actinomycetemcomitans.

\section{DISCUSSION}

In this study we have identified and isolated the gene encoding MsrA activity in A. actinomycetemcomitans strain SUNY 465. MsrA is a ubiquitous protein that has been found in both eukaryotic and prokaryotic organisms (Cao et al., 1998; Dhandayuthapani et al., 2001; Hassouni et al., 1999; Moskovitz et al., 1996b, 1998; Rahman et al., 1992; Vriesema et al., 2000; Wizemann et al., 1996). The amino acid sequence identity ranges between $33 \%$ and $88 \%$ among members of this family (Lowther et al., 2000). The A. actinomycetemcomitans MsrA has the greatest amino acid homology with the MsrA of $H$. pylori. Based on the protein sequence, both of these sequences appear to contain a cleavable signal sequence based on signal sequence algorithms (http://psort.nibb.ac.jp/form. html). None of the other bacterial MsrA proteins investigated contained these sequences. Recently, a fragment of DNA encoding the signal sequence and a portion of the A. actinomycetemcomitans MsrA was identified using alkaline phosphatase fusions of secreted proteins (Ward et al., 2001). In fact, the gene encoding 
the H. pylori MsrA was isolated using antisera raised against antigens found in broth culture supernatants (Cao et al., 1998). More recently, two forms of the $N$. gonorrhoeae homology of MsrA (PilB) have been shown to be synthesized (Skaar et al., 2002). One form of the polypeptide contains a signal sequence and is secreted from the bacterial cytoplasm to the outer membrane. The other form of the protein lacks a signal sequence and is cytoplasmic. Taken together, these examples and the data presented in this study suggest that MsrA of A. actinomycetemcomitans is transported across the cytoplasmic membrane in a sec-dependent pathway.

The protein from H. pylori is suggested to be released into the extracellular space by multiple mechanisms including specific secretion pathways, autolysis and membrane vesicle formation (Cao et al., 1998). The results in this study suggest that MsrA of A. actinomycetemcomitans is transported across the cytoplasmic membrane and is most likely located in the periplasmic space or loosely associated with the inner membrane. A. actinomycetemcomitans also secretes membranous vesicles (Lai et al., 1981; Meyer \& Fives-Taylor, 1994; Nowotny et al., 1982) and therefore may release the enzyme in a manner analogous to $H$. pylori.

The protective role of MsrA to oxidative damage has been demonstrated in a number of bacterial systems (Dhandayuthapani et al., 2001; Hassouni et al., 1999; Moskovitz et al., 1995; Vriesema et al., 2000). However, the data presented in this study indicate that MsrA of A. actinomycetemcomitans is not the predominant mechanism that protects the organism against oxidative damage. A. actinomycetemcomitans has been shown to contain a single gene for catalase, but may contain other undefined mechanisms to inactivate hydrogen peroxide (Thomson et al., 1999). In addition, a $\mathrm{Cu}^{2+}-\mathrm{Zn}^{2+}$ superoxide dismutase homologue has also been identified (Fletcher et al., 2001). Therefore, it is possible that these systems mask the antioxidant defence mechanism provided by MsrA. Interestingly, the $A$. actinomycetemcomitans strain overexpressing MsrA activity at levels $8-10$ times that of wild-type levels did not show any difference in growth inhibition compared with the parent strain in disk inhibition assays (data not shown).

Downstream of $m s r A$ is an ORF encoding an MsrB homologue, which exhibits a high specificity for reduction of the $R$ forms of free and protein-bound methionine sulfoxide (Moskovitz et al., 2002). MsrA exhibits a high specificity for the reduction of the $S$ form of the substrates. The substrate used in the detection of MsrA enzymic activity contains both $R$ and $S$ stereoisomer forms (J. Moskovitz, unpublished). Therefore, the complete absence of enzymic activity in the mutant strain suggests that disruption of $m s r A$ also results in the loss of MsrB activity. This suggests that the disruption of $m s r A$ in this study has a polar effect on $m s r B$ transcription. $m s r A$ and $m s r B$ have been determined to be transcribed as part of a polycistronic message in Sta. aureus (Singh et al., 2001).
MsrB shares sequence homology with PilB of $N$. gonorrhoeae, a transcriptional regulator. Therefore, a regulatory function for $\mathrm{MsrB}$ is plausible and may explain the results of the complementation studies. Wild-type levels of enzyme activity were achieved following transformation of the mutant strain with a low-copy-number plasmid containing $m s r A$. This result by itself would suggest that $m s r B$ transcription was not affected by the disruption of msrA. However, transformation of the parent strain with the same plasmid increased enzymic activity up to 10 times that found in the same strain when transformed with the plasmid backbone. This dramatic difference suggests that a gene product(s) that is present in the parent strain, that results in increased enzymic activity when msrA is presented in trans is inactive in the mutant strain. Taken together, the results suggest that inactivation of $m s r A$ results in a polar mutation that disrupts $m s r B$ transcription and that $m s r A$ and $m s r B$ are transcribed as a polycistronic mRNA. In addition, the data also suggest that MsrB regulates transcription of $m s r A$ in A. actinomycetemcomitans. A msrB mutant is being constructed to investigate this hypothesis.

The inactivation of $m s r A$ in other organisms has led to changes in the surface ligands and adherence of multiple bacterial species. Genetic inactivation of $m s r A$ in Str. pneumoniae leads to a dramatic reduction in bacterial adherence (Wizemann et al., 1996). In enteropathogenic E. coli, loss of MsrA activity decreased type I fimbriaemediated haemagglutination and restoration of the enzymic activity by introduction of plasmid containing $m s r A$ restored the haemagglutination activity back to wild-type levels. In contrast to a loss of surface ligands in $m s r A$ mutants, a hyperpiliation and hyperadherent phenotype is observed in N. gonorrhoeae msr A mutants (Taha et al., 1988; Wizemann et al., 1996). MsrA of N. gonorrhoeae is encoded by pilB, which is part of the pilA-pilB locus that is involved in transcriptional regulation of the expression of the pilin subunit, pilE (Taha et al., 1988, 1992). In our study with $A$. actinomycetemcomitans, inactivation of $m s r A$, which results in abolishing the enzymic activity, does not affect the binding of the bacterium to epithelial cells.

Fresh isolates of $A$. actinomycetemcomitans from the oral cavity grow in a heavily fimbriated, rough phenotype (Inouye et al., 1990; Preus et al., 1988; Rosan et al., 1988; Scannapieco et al., 1987). Following continuous in vitro culturing, many of the isolates lose some of the fimbriae and display a smooth phenotype. The isolate used in this study displays some fimbriae, displays a smooth phenotype and adheres to multiple surfaces (Meyer \& Fives-Taylor, 1994; Mintz \& Fives-Taylor, 1994, 1999). The nature or number of the adhesins in $A$. actinomycetemcomitans is still ill-defined. Therefore, the lack of effect due to the disruption of $m s r A$ suggests that MsrA activity is either not involved in 1) the maintenance of the biological activity of the adhesin(s); 2) the regulation at the level of transcription of the adhesin or 3) that redundant adhesin molecules are present at the cell surface and inactivation of a single 
adhesin does not diminish the binding activity or the reduction in activity is below the sensitivity of the assay used in this study.

Methionine sulfoxide reductase has been described for a variety of organisms and common characteristics have been established. Before this study, this gene or gene product had not been characterized from an oral pathogen. In this study, a series of experiments have been attempted to demonstrate the protective role of MsrA as an antioxidant. However, the data suggests that this enzyme may only serve a minor role in the protection of the organism against oxidative damage. A wealth of evidence also exists that demonstrates the role of MsrA as a virulence determinant for pathogenesis in terms of adherence and motility of microorganisms (Hassouni et al., 1999; Wizemann et al., 1996). In A. actinomycetemcomitans SUNY 465, the data indicate that MsrA is not involved in the stabilization or regulation of adhesin(s) mediating the interaction of the bacterium with human epithelial cells. Although in vitro models may provide insight into potential protein function, the role of MsrA in vivo awaits the development of suitable animal model systems for periodontal disease.

\section{ACKNOWLEDGEMENTS}

We would like to thank Mingyuan Shao for cloning msrA, Akamol Suvarnapunya for his assistance in the macrophage survival studies and Bruce Roe at the University of Oklahoma's Advanced Center for Genome Technology for providing the A. actinomycetemcomitans HK1651 nucleotide sequence. This work was supported by Public Health Service grant RO1-DE09760 and in part by RO1-DE13824.

\section{REFERENCES}

Asikainen, S. \& Alaluusua, S. (1993). Bacteriology of dental infections. Eur Heart J 14 Suppl K, 43-50.

Berghammer, H. \& Auer, B. (1993). 'Easypreps': fast and easy plasmid minipreparation for the analysis of recombinant clones in E. coli. Biotechniques 14, 527-528.

Brot, N. \& Weissbach, H. (1991). Biochemistry of methionine sulfoxide residues in proteins. Biofactors 3, 91-96.

Brot, N., Weissbach, L., Werth, J. \& Weissbach, H. (1981). Enzymatic reduction of protein-bound methionine sulfoxide. Proc Natl Acad Sci US A 78, 2155-2158.

Cao, P., McClain, M. S., Forsyth, M. H. \& Cover, T. L. (1998). Extracellular release of antigenic proteins by Helicobacter pylori. Infect Immun 66, 2984-2986.

Dhandayuthapani, S., Blaylock, M. W., Bebear, C. M., Rasmussen, W. G. \& Baseman, J. B. (2001). Peptide methionine sulfoxide reductase (MsrA) is a virulence determinant in Mycoplasma genitalium. J Bacteriol 183, 5645-5650.

Feilmeier, B. J., Iseminger, G., Schroeder, D., Webber, H. \& Phillips, G. J. (2000). Green fluorescent protein functions as a reporter for protein localization in Escherichia coli. J Bacteriol 182, 4068-4076.

Fives-Taylor, P. M., Meyer, D. H., Mintz, K. P. \& Brissette, C. (1999). Virulence factors of Actinobacillus actinomycetemcomitans. Periodontol 2000 20, 136-167.

Fletcher, J. M., Nair, S. P., Ward, J. M., Henderson, B. \& Wilson, M.
(2001). Analysis of the effect of changing environmental conditions on the expression patterns of exported surface-associated proteins of the oral pathogen Actinobacillus actinomycetemcomitans. Microb Pathog 30, 359-368.

Guy, R. L., Gonias, L. A. \& Stein, M. A. (2000). Aggregation of host endosomes by Salmonella requires SPI2 translocation of sseFG and involves $s p v R$ and the fms-aroE intragenic region. Mol Microbiol 37, 1417-1435.

Hassouni, M. E., Chambost, J. P., Expert, D., Van Gijsegem, F. \& Barras, F. (1999). The minimal gene set member msrA, encoding peptide methionine sulfoxide reductase, is a virulence determinant of the plant pathogen Erwinia chrysanthemi. Proc Natl Acad Sci US A 96, 887-892.

Inouye, T., Ohta, H., Kokeguchi, S., Fukui, K. \& Kato, K. (1990). Colonial variation and fimbriation of Actinobacillus actinomycetemcomitans. FEMS Microbiol Lett 57, 13-17.

Kaplan, A. H., Weber, D. J., Oddone, E. Z. \& Perfect, J. R. (1989). Infection due to Actinobacillus actinomycetemcomitans: 15 cases and review. Rev Infect Dis 11, 46-63.

Kuschel, L., Hansel, A., Schonherr, R., Weissbach, H., Brot, N., Hoshi, T. \& Heinemann, S. H. (1999). Molecular cloning and functional expression of a human peptide methionine sulfoxide reductase (hMsrA). FEBS Lett 456, 17-21.

Lai, C. H., Listgarten, M. A. \& Hammond, B. F. (1981). Comparative ultrastructure of leukotoxic and non-leukotoxic strains of Actinobacillus actinomycetemcomitans. J Periodontal Res 16, 379-389.

LeBlanc, D. J., Lee, L. N. \& Inamine, J. M. (1991). Cloning and nucleotide base sequence analysis of a spectinomycin adenyltransferase $\mathrm{AAD}(9)$ determinant from Enterococcus faecalis. Antimicrob Agents Chemother 35, 1804-1810.

LeBlanc, D. J., Lee, L. N., Abu-Al-Jaibat, A. R., Sreenivasan, P. K. \& Fives-Taylor, P. M. (1993). Identification of plasmids in Actinobacillus actinomycetemcomitans and construction of intergeneric shuttle plasmids. Oral Microbiol Immunol 8, 94-99.

Lowther, W. T., Brot, N., Weissbach, H., Honek, J. F. \& Matthews, B. W. (2000). Thiol-disulfide exchange is involved in the catalytic mechanism of peptide methionine sulfoxide reductase. Proc Natl Acad Sci U S A 97, 6463-6468.

Meyer, D. H. \& Fives-Taylor, P. M. (1994). Characteristics of adherence of Actinobacillus actinomycetemcomitans to epithelial cells. Infect Immun 62, 928-935.

Mintz, K. P. \& Fives-Taylor, P. M. (1994). Adhesion of Actinobacillus actinomycetemcomitans to a human oral cell line. Infect Immun 62, 3672-3678.

Mintz, K. P. \& Fives-Taylor, P. M. (1999). Binding of the periodontopathogen Actinobacillus actinomycetemcomitans to extracellular matrix proteins. Oral Microbiol Immunol 14, 109-116.

Mintz, K. P. \& Fives-Taylor, P. M. (2000). impA, a gene coding for an inner membrane protein, influences colonial morphology of Actinobacillus actinomycetemcomitans. Infect Immun 68, 65806586.

Mintz, K. P., Brissette, C. \& Fives-Taylor, P. M. (2002). A recombinase A-deficient strain of Actinobacillus actinomycetemcomitans constructed by insertional mutagenesis using a mobilizable plasmid. FEMS Microbiol Lett 206, 87-92.

Moskovitz, J., Rahman, M. A., Strassman, J., Yancey, S. O., Kushner, S. R., Brot, N. \& Weissbach, H. (1995). Escherichia coli peptide methionine sulfoxide reductase gene: regulation of expression and role in protecting against oxidative damage. J Bacteriol 177, 502-507.

Moskovitz, J., Jenkins, N. A., Gilbert, D. J., Copeland, N. G., 
Jursky, F., Weissbach, H. \& Brot, N. (1996a). Chromosomal localization of the mammalian peptide-methionine sulfoxide reductase gene and its differential expression in various tissues. Proc Natl Acad Sci US A 93, 3205-3208.

Moskovitz, J., Weissbach, H. \& Brot, N. (1996b). Cloning and the expression of a mammalian gene involved in the reduction of methionine sulfoxide residues in proteins. Proc Natl Acad Sci US A 93, 2095-2099.

Moskovitz, J., Flescher, E., Berlett, B. S., Azare, J., Poston, J. M. \& Stadtman, E. R. (1998). Overexpression of peptide-methionine sulfoxide reductase in Saccharomyces cerevisiae and human $\mathrm{T}$ cells provides them with high resistance to oxidative stress. Proc Natl Acad Sci U S A 95, 14071-14075.

Moskovitz, J., Berlett, B. S., Poston, J. M. \& Stadtman, E. R. (1999). Methionine sulfoxide reductase in antioxidant defence. Methods Enzymol 300, 239-244.

Moskovitz, J., Poston, J. M., Berlett, B. S., Nosworthy, N. J., Szczepanowski, R. \& Stadtman, E. R. (2000). Identification and characterization of a putative active site for peptide methionine sulfoxide reductase (MsrA) and its substrate stereospecificity. J Biol Chem 275, 14167-14172.

Moskovitz, J., Bar-Noy, S., Williams, W. M., Requena, J., Berlett, B. S. \& Stadtman, E. R. (2001). Methionine sulfoxide reductase (MsrA) is a regulator of antioxidant defense and lifespan in mammals. Proc Natl Acad Sci US A 98, 12920-12925.

Moskovitz, J., Singh, V. K., Requena, J., Wilkinson, B. J., Jayaswal, R. K. \& Stadtman, E. R. (2002). Purification and characterization of methionine sulfoxide reductase from mouse and Staphylococcus aureus and their substrate stereospecificity. Biochem Biophys Res Commun 290, 62-65.

Nowotny, A., Behling, U. H., Hammond, B., Lai, C. H., Listgarten, M., Pham, P. H. \& Sanavi, F. (1982). Release of toxic microvesicles by Actinobacillus actinomycetemcomitans. Infect Immun 37, 151-154.

Ochman, H., Ajoka, J. W., Garaza, D. \& Hartl, D. L. (1989). Inverse polymerase chain reaction. In PCR Technology: Principles and Applications for DNA Amplification, pp. 105-111. Edited by H. A. Erlich. New York: Stockton Press.

Preus, H. R., Namork, E. \& Olsen, I. (1988). Fimbriation of Actinobacillus actinomycetemcomitans. Oral Microbiol Immunol 3, 93-94.

Rahman, M. A., Nelson, H., Weissbach, H. \& Brot, N. (1992). Cloning, sequencing, and expression of the Escherichia coli peptide methionine sulfoxide reductase gene. J Biol Chem 267, 15549-15551.

Rosan, B., Slots, J., Lamont, R. J., Listgarten, M. A. \& Nelson, G. M. (1988). Actinobacillus actinomycetemcomitans fimbriae. Oral Microbiol Immunol 3, 58-63.

Sambrook, J., Fritsch, E. F. \& Maniatis, T. (1989). Molecular Cloning: a Laboratory Manual, 2nd edn. Cold Spring Harbor, NY : Cold Spring Harbor Laboratory.

Scannapieco, F. A., Millar, S. J., Reynolds, H. S., Zambon, J. J. \& Levine, M. J. (1987). Effect of anaerobiosis on the surface ultrastructure and surface proteins of Actinobacillus actinomycetemcomitans (Haemophilus actinomycetemcomitans). Infect Immun 55, 2320-2323.

Singh, V. K., Moskovitz, J., Wilkinson, B. J. \& Jayaswal, R. K. (2001). Molecular characterization of a chromosomal locus in Staphylococcus aureus that contributes to oxidative defence and is highly induced by the cell-wall-active antibiotic oxacillin. Microbiology 147, 3037-3045.

Skaar, E. P., Tobiason, D. M., Quick, J., Judd, R. C., Weissbach, H., Etienne, F., Brot, N. \& Seifert, H. S. (2002). The outer membrane localization of the Neisseria gonorrhoeae MsrA/B is involved in survival against reactive oxygen species. Proc Natl Acad Sci U S A 99, 10108-10113.

Slots, J., Bragd, L., Wikstrom, M. \& Dahlen, G. (1986). The occurrence of Actinobacillus actinomycetemcomitans, Bacteroides gingivalis and Bacteroides intermedius in destructive periodontal disease in adults. J Clin Periodontol 13, 570-577.

Sreenivasan, P. K., LeBlanc, D. J., Lee, L. N. \& Fives-Taylor, P. M. (1991). Transformation of Actinobacillus actinomycetemcomitans by electroporation, utilizing constructed shuttle plasmids. Infect Immun 59, 4621-4627.

Sreenivasan, P. K., Meyer, D. H. \& Fives-Taylor, P. M. (1993). Factors influencing the growth and viability of Actinobacillus actinomycetemcomitans. Oral Microbiol Immunol 8, 361-369.

Storz, G. \& Imlay, J. A. (1999). Oxidative stress. Curr Opin Microbiol 2, 188-194.

Taha, M. K., So, M., Seifert, H. S., Billyard, E. \& Marchal, C. (1988). Pilin expression in Neisseria gonorrhoeae is under both positive and negative transcriptional control. EMBO J 7, 4367-4378.

Taha, M. K., Larribe, M., Dupuy, B., Giorgini, D. \& Marchal, C. (1992). Role of pilA, an essential regulatory gene of Neisseria gonorrhoeae, in the stress response. J Bacteriol 174, 5978-5981.

Thomson, V. J., Bhattacharjee, M. K., Fine, D. H., Derbyshire, K. M. \& Figurski, D. H. (1999). Direct selection of IS 903 transposon insertions by use of a broad-host-range vector: isolation of catalase-deficient mutants of Actinobacillus actinomycetemcomitans. J Bacteriol 181, 7298-7307.

Tomb, J. F., White, O., Kerlavage, A. R. \& 39 other authors (1997). The complete genome sequence of the gastric pathogen Helicobacter pylori. Nature 388, 539-547.

von Heijne, G. (1986). A new method for predicting signal sequence cleavage sites. Nucleic Acids Res 14, 4683-4690.

Vriesema, A. J., Dankert, J. \& Zaat, S. A. (2000). A shift from oral to blood $\mathrm{pH}$ is a stimulus for adaptive gene expression of Streptococcus gordonii $\mathrm{CH} 1$ and induces protection against oxidative stress and enhanced bacterial growth by expression of msrA. Infect Immun 68, 1061-1068.

Ward, J., Fletcher, J., Nair, S. P., Wilson, M., Williams, R. J., Poole, S. \& Henderson, B. (2001). Identification of the exported proteins of the oral opportunistic pathogen Actinobacillus actinomycetemcomitans by using alkaline phosphatase fusions. Infect Immun 69, 2748-2752.

Wizemann, T. M., Moskovitz, J., Pearce, B. J., Cundell, D., Arvidson, C. G., So, M., Weissbach, H., Brot, N. \& Masure, H. R. (1996). Peptide methionine sulfoxide reductase contributes to the maintenance of adhesins in three major pathogens. Proc Natl Acad Sci U S A 93, 7985-7990.

Zadeh, H. H., Nichols, F. C. \& Miyasaki, K. T. (1999). The role of the cell-mediated immune response to Actinobacillus actinomycetemcomitans and Porphyromonas gingivalis in periodontitis. Periodontol 2000 20, 239-288.

Zambon, J. J. (1985). Actinobacillus actinomycetemcomitans in human periodontal disease. J Clin Periodontol 12, 1-20.

Received 10 April 2002; revised 15 July 2002; accepted 1 August 2002. 